\title{
Pain management in the emergency department: results from an observational longitudinal prospective study in a second-level urban hospital
}

\author{
Anna Giulia Falchi, ${ }^{1}$ Anna Spadoni, ${ }^{1}$ Chiara Blatti, ${ }^{1}$ Federica Manzoni, ${ }^{2}$ Stefano Perlini, ${ }^{1}$ \\ OSM acute pain assessment lab*
}

${ }^{1}$ Emergency Department, IRCCS Policlinico San Matteo Foundation, University of Pavia; ${ }^{2}$ Clinical Epidemiology and Biometry Unit, Scientific Direction, San Matteo Hospital Foundation, Pavia, Italy

\begin{abstract}
Although a correct assessment of pain and an adequate analgesia represent a priority in the setting of emergency care, many studies documented an inadequate pain control. The purpose of our study is to characterize the present status of a second level Emergency Department in Italy in terms of pain assessment and treatment. Our survey investigates the multidimensional aspects of pain, the accomplishment of appropriate pain evaluation by the medical and nursing staff and the effectiveness of the treatment, in terms of pain reduction and also of customer satisfaction.
\end{abstract}

\section{Introduction}

According to literature, pain is the first cause of access to Emergency Departments (ED) accounting for of $52-78 \%$ of admissions. ${ }^{1}$ Adequate analgesia is fundamental in urgency; however numerous studies have documented an inadequate pain control both in the prehospital setting and in the ED, highlighting the tendency of only a systematic oligoanalgesia (undertreatment). ${ }^{2-4}$ Few results have been achieved for what

\footnotetext{
Correspondence: Anna Giulia Falchi, Emergency Department, IRCCS Fondazione Policlinico San Matteo, Piazzale Golgi 19, 27100 Pavia Italy

E-mail: a.falchi@smatteo.pv.it

Key words: Pain Assessment; Emergency Medicine; Acute Pain; Pain Management.

Conflict of interst: the authors declare no potential conflict of interests. Ethical statement: this study has been approval by the Ethical Committee of Area Vasta Pavia on 20/11/2017 (acceptance nr. 20170004196).

Received for publication: 3 February 2020.

Accepted for publication: 18 May 2020.

This work is licensed under a Creative Commons Attribution 4.0 License (by-nc 4.0).

${ }^{\circ}$ Copyright: the Author(s), 2020

Licensee PAGEPress, Italy

Emergency Care Journal 2020; 16:8871

doi:10.4081/ecj.2020.8871
}

concerns time-to-treatment reduction and improvement in pain evaluation and administration of analgesia. This has been confirmed by a large multicenter study ${ }^{5}$ independent of the type of pain, the level of intensity, of the patients' request (i.e. either seeking or not overtly asking for analgesic treatment). In the Emergency Care setting a correct assessment and treatment of pain is a priority, as well as a quality indicator. ${ }^{6}$ Several attempts to improve pain management in the ED have been made implementing patient's assessment through pain scales, ${ }^{7}$ and by personnel training. Measuring pain is necessary for evaluation, using simple, effective and validated tools, for analysis of the trend over time, for the choice of the appropriate analgesic approach, and to share a common language between the healthcare professionals. A multidimensional evaluation of pain in ED aimed at a diagnostic as well as a therapeutic approach is fundamental and should include: quality, severity, chronicity, contributing or associated factors, location and distribution or, if known, aetiology of pain, mechanism of injury (when feasible), and barriers to pain assessment. Pain assessment represents the basis of pain management, ${ }^{8}$ since diagnosis, and grading enables a proper decision on the choice of the most appropriate analgesic treatment. Management of acute pain in ED should be patient-centred and pain-syndrome-targeted and should combine non-pharmacological and pharmacological analgesic interventions. It is critical to treat acute pain also to maximize healing and to minimize the chances of progression to a chronic pain condition. ${ }^{9}$ Despite extensive research on the identification of factors leading to poor pain management and development of evidence-based strategies, the transfer of this knowledge into effective clinical practices is still lacking. The purpose of our study is to characterize the present status of our ED for what concerns pain evaluation and treatment, and to improve the relevant performance.

The patient-oriented primary goal of the study is to reduce pain scores evaluated by a pain intensity rating at admission and after analgesic treatment by using NRS scale ${ }^{10} 0$ to 10 . Patient satisfaction will be considered as a measure of medical provider responsiveness to his pain and effective communication between patients and the medical providers.

\section{Material and Methods}

\section{Study design}

The study was carried out in accordance with the standards of good clinical practice and with the current version of the World Medical Association Declaration of Helsinki. ${ }^{11}$ The "Prospective Longitudinal Observational Study for the Improvement of the Detection and Treatment of Pain in the Emergency Room" was 
designed in the ED of IRCCS Policlinico San Matteo Foundation in Pavia, Italy, and was approved by the Ethical Committee of Area Vasta - Pavia on 20/11/2017 (Prot 20170004196). The study protocol was drawn up in accordance with the STROBE guidelines for observational studies. ${ }^{12}$ This is a monocentric, observational, longitudinal and prospective study, enrolling patients complaining of pain upon admission, with the exclusion of chest pain. Patients were collected for 7 consecutive days, for a sample of 5 weeks, and for an overall duration of 15 months. A team of residents in Emergency Medicine, called O.S.M. acute pain assessment lab., began carrying out sample data recording continuously of all the patients accessing to ED at the different shifts of day and night in all the areas of the emergency room (minor care, acute care, trauma unit and short-stay observation). Patients should be able to express an informed consent. A total number of 307 patients were enrolled in the study between $14^{\text {th }}$ December 2017 to $28^{\text {th }}$ February 2019. Patients were asked to participate in this study at the end of their ED stay just before discharge, after being selected according to the following eligibility criteria: age at least 18 years, pain complaint upon ED admission

After correct detailed information about the study purpose and signature of the informed consent, the patient received an approved standardized questionnaire aimed at collecting the following data: comorbidities, previous ED accesses for analogue pain, previous analgesic therapy, waiting time. Specifically, the patient was asked at first to rate, on the basis of NRS scale 0 to 10 , the pain intensity both at admission and after therapy and subsequently to evaluate, on a scale 0 to 10 , his perception of the received care quality (general care, medical care, nursing care, information adequacy). Additional data were collected from the medical records in terms of care area, priority code, pain intensity both in triage and during the visit, diagnosis of the type of pain (and in case of post traumatic pain all possible details about the trauma), administered therapy (drug, dose, administration and frequency route) and treatment indications, final discharge, follow-up, hospitalization.

This study is non-profit, with no costs both for the institution and the patients. The medical personnel participated in data collection for this study on a voluntary basis, thus has not received any type of compensation. The only tools needed for the study included: hard copies of the survey, electronic medium (i.e. tablet) for data collection, copies of the informed consent, medical records of the enrolled patients and volunteering medical personnel. All the procedures for data collection were completed in spaces and times chosen to avoid any kind of interference with clinical activities.

COMORBIDITIES

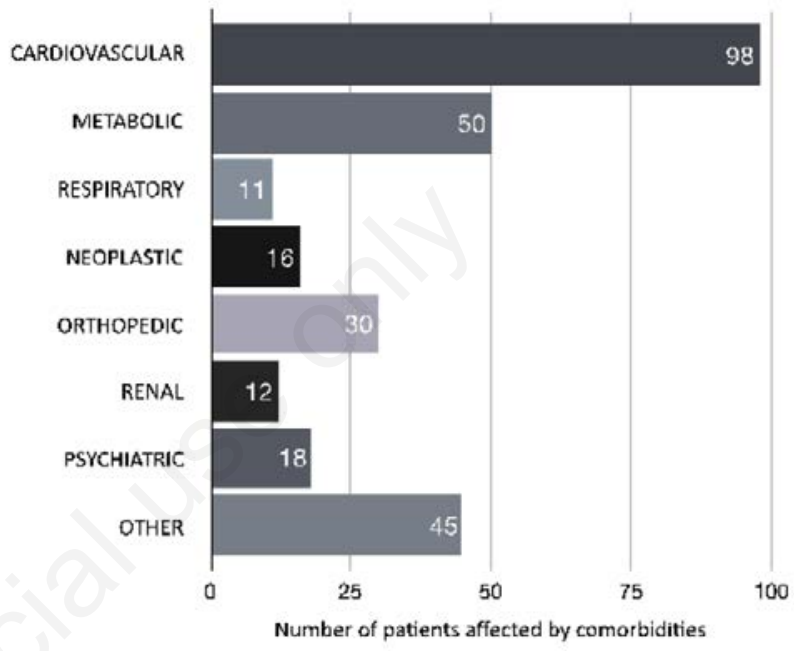

Figure 1. Comorbidities in patients.

Table 1. Sociodemographic baseline characteristics of the study population.

\begin{tabular}{|c|c|c|c|}
\hline & Patient characteristics & N. & $\%$ \\
\hline Gender & $\begin{array}{l}\text { Males } \\
\text { Females }\end{array}$ & $\begin{array}{l}137 \\
170\end{array}$ & $\begin{array}{l}44.6 \\
55.4\end{array}$ \\
\hline Age & Years, median \pm SD (range) & $50 \pm 19$ & 7.97 \\
\hline Nationality & $\begin{array}{l}\text { Italian } \\
\text { European } \\
\text { Non-European }\end{array}$ & $\begin{array}{c}269 \\
18 \\
20\end{array}$ & $\begin{array}{c}87.6 \\
5.9 \\
6.5\end{array}$ \\
\hline Level of education & $\begin{array}{l}\text { None } \\
\text { Primary school diploma } \\
\text { Middle school diploma } \\
\text { High school diploma } \\
\text { University degree } \\
\text { Not answered }\end{array}$ & $\begin{array}{c}3 \\
63 \\
98 \\
117 \\
23 \\
3 \\
\end{array}$ & $\begin{array}{c}1 \\
20.5 \\
31.9 \\
38.1 \\
7.5 \\
1\end{array}$ \\
\hline Comorbidities & $\begin{array}{l}\text { Cardiovascular } \\
\text { Metabolic } \\
\text { Respiratory } \\
\text { Neoplastic } \\
\text { Orthopaedic } \\
\text { Renal } \\
\text { Psychiatric } \\
\text { Other }\end{array}$ & $\begin{array}{l}98 \\
50 \\
11 \\
16 \\
30 \\
12 \\
18 \\
45\end{array}$ & $\begin{array}{c}31.9 \\
16.3 \\
3.6 \\
5.2 \\
9.8 \\
3.9 \\
5.9 \\
14.6\end{array}$ \\
\hline Priority code & $\begin{array}{l}\text { White } \\
\text { Green } \\
\text { Yellow } \\
\text { Red }\end{array}$ & $\begin{array}{c}12 \\
237 \\
56 \\
2\end{array}$ & $\begin{array}{c}3.9 \\
77.2 \\
18.2 \\
0.7\end{array}$ \\
\hline
\end{tabular}




\section{Statistical methods}

\section{Sample size considerations}

The sample size of 307 patients allows us to estimate a percentage of $76.8 \%(n=236)$ of patients with severe pain before entering the emergency room/waiting in triage with a precision of $5 \%$, calculated as half of the binomial exact $95 \%$ confidence interval. Categorical variables were described with counts and percentages; quantitative variables were expressed as mean and standard deviation (sd), after checking for normality of the distribution. Continuous variables were compared between two groups with the Student's t test. All tests were two-sided, with an alpha level of significance set at 0.05 ( $\mathrm{p}$ value $<0.05$ for statistical significance).

\section{Results}

A total amount of 307 patients who presented to the Emergency Department of IRCCS Fondazione Policlinico San Matteo of Pavia from 14 ${ }^{\text {th }}$ December 2017 to $28^{\text {th }}$ February 2019 were enrolled in the current study and analysed.

\section{Characteristics of the study population}

The sociodemographic baseline characteristics are represented in Table 1. Regarding the clinical history, 98 patients had cardiovascular diseases, 50 had metabolic comorbidities, 11 had respiratory diseases, 16 had neoplastic diseases, 30 had orthopaedic comorbidities, 12 had renal disorders, 18 presented psychiatric disorders, and 45 patients declared other comorbidities (Figure 1). Patients were randomly recruited on the seven days of the week during all the different day and night shifts to minimize the risk of errors due to patient selection. The acquired data reflect the real distribution of patients with pain in the different areas of intensity of care. 221 patients $(72 \%)$ were enrolled in minor care unit, 14 $(4.6 \%)$ in acute care unit, $56(18.2 \%)$ in trauma unit, and $16(5.2 \%)$ in the ED observation unit. Of these, 12 (3.9\%) were admitted with a white code, $237(77.2 \%)$ with a green code, $56(18.2 \%)$ with a yellow code, $2(0.7 \%)$ with red code.

\section{History of pain}

The majority of questions addressed to patients were aimed at evaluating qualities and history of pain. Different aspects such as duration of pain, number of admissions for analogue type of pain in the last 3, 6 and 12 months, and the presence of a home-based analgesic therapy, have been investigated (Table 2). These figures confirm that the majority of ED accesses are related to acute disorders. Furthermore, only 50 patients $(16.2 \%)$ were already on a home-based analgesic therapy. It is interesting to note that this number is very close to the number of patients who were previously admitted to the ED for a similar type of pain (58 patients, $18.9 \%$ ). It therefore appears evident that the majority of patients with persistent-to-chronic pain had already received a therapeutic schedule prescribed by primary care physician, although not sufficient for an adequate home-based management.

\section{Pain characteristics}

Patients reported the intensity of pain that caused their referral to the ED, quantifiable through NRS scale[x] or the degree/intensity of pain while waiting in triage. The same question was repeated after the administration of analgesic therapy. Interestingly, as reported in Table 2, the average NRS value decreased from 7.9 (sd1.8) upon admission to $4.3(\mathrm{sd} 2.8)$ after treatment, a highly statistically significant difference $(\mathrm{p}<0.0001)$. This confirms the effi- cacy of the therapy administered by the ED physician during the visit. The following categories of pain were observed: visceral abdominal pain $(44.6 \%)$, musculoskeletal pain, either traumatic $(28.6 \%)$ or non-traumatic $(9.7 \%)$, headache $(8.4 \%)$, neuropathic pain (3\%), cancer pain (3\%) and post-operative (1\%) (Table 2). As reported in Table 3, the reduction in pain intensity between triage enrolment and after administration of therapy was statistically significant in non-traumatic musculoskeletal pain $(\mathrm{p}<0.0001)$, posttraumatic pain $(\mathrm{p}<0.0001)$, abdominal pain $(\mathrm{p}<0.0001)$ and headache $(\mathrm{p}<0.0001)$, whereas no significant change was reported in patients complaining of cancer pain $(p<0.26)$ and neuropathic pain $(\mathrm{p}<0.08)$, i.e. settings that are likely to require a more specialized target therapy from the pathophysiological standpoint, and do not usually respond to the first-level therapy given in ED. In general terms, the disease that seems to cause the highest pain intensity is oncological pain, 9 (sd1.7): this is quite significant if we think that most of these patients are already on chronic treatment; cancer pain is followed by headache 8.4 (sd 1.6), abdominal pain 8.3 (sd 1.6), neuropathic pain 8.3 (sd 0.5 ), non-traumatic musculoskeletal pain 7.4 (sd 2.1) and traumatic pain 7.1(sd 2.2).

\section{Pharmacological treatment}

\section{Time to analgesia (measured from triage)}

Out of 307 patients, 237 (77.2\% of the population analysed) received analgesic therapy, while 70 did not $(22.8 \%)$ Among the ones who received it, the majority ( $46.6 \%$ of the total) had to wait less than 10 minutes; a minor part waited between 11-20 minutes (5.8\%) and between 21-30 minutes (3.9\%); the remaining ones, which represent a quite consistent part of the sample (16\%), were administered the analgesic therapy after a longer time, either between $31-60$ minutes (7.2\%) or after 60 minutes $(8.8 \%)$. Furthermore, among those who did not receive any treatment, 51 patients did not ask for it (16.6\%), while the remaining 19 patients $(6.2 \%)$ have declared to have received no treatment despite asking for it. In addition to the first therapy, 55 patients (17.9\%) had to ask for a second treatment/dose/administration due to persistent pain: the majority had to wait less than 1 hour to receive it (41 patients), 12 of them had to wait approximately 1 to 2 hours, while 2 of them received it after 3-4 hours.

\section{Pharmacological treatment}

Among the analgesics, the most frequently used were Paracetamol (administered 99 times as intravenous drug and 25 as oral drug), Ketorolac (dispensed 62 times by intravenous route and 21 times by intramuscular route), and Tramadol (21 times, intravenous), followed by morphine given 10 times, Lidocaine 9 times (used as local anesthetic for peripheral nerve blocks for fractures), Diclofenac 7 times, Indomethacin 7 times, Ketoprofen twice, and Sufentanil used only once. From these data, we can also conclude that the intravenous route of administration for analgesics is preferred over the oral, intramuscular and subcutaneous ones. The administration of Paracetamol was 99 times intravenous and only 25 times oral (500 or $1000 \mathrm{mg}$ ); Ketorolac was administered intravenously 62 times and intramuscularly 21 times, Diclofenac only intramuscularly while Ketoprofen, Tramadol, Morphine and Sufentanil only intravenously.

Paracetamol alone is the single most used drug (used 124 times), followed by nonsteroidal anti-inflammatory drugs [NSAIDs] (99), opioids (32) and Lidocaine (9). A total of 137 patients $(44,6 \%$ of cases) complained abdominal pain, with mean NRS 8.3 (sd 1.6); among these, 56 patients were treated with Paracetamol and 40 patients with NSAIDs, 10 patients received opiates. The adjuvants used are mainly gastroprotectors and 
antiemetics, besides anti-anxiety medications (benzodiazepines [BZs]) A total of 26 headaches were enrolled (8.4\%), with mean NRS 8.4, (sd 1.6), representing the second most intense pain after cancer pain. 20 patients received NSAIDs (Indometacine or Ketorolac), 6 patients received Paracetamol. Anxiolytics (BZs) and antihypertensives are used as adjuvants.
The correlation between pain intensity and choice of therapy has also been investigated (Figure 2). Pain intensity was divided into three categories according to NRS value reported by patients upon arrival to ER: mild means a value between 1 and 3, moderate 4 to 6 , severe 7 to 10 . Most of the people presenting with mild pain were not treated $(90 \%)$, while the remaining ones $(10 \%)$ were

Table 2. Pain characteristics according to descriptor categories.

\begin{tabular}{|c|c|c|}
\hline Pain anamnesis & N. of patients & $\%$ \\
\hline $\begin{array}{l}\text { Number of acute admissions to ED for analogue pain } \\
\text { No admissions to ED in the last } 12 \text { months } \\
\text { Admissions in the last } 12 \text { months } \\
\text { - In the last } 3 \text { months ( } 33 \text { from } 1 \text { to } 3 \text { times and } 1 \text { for }>3 \text { times) } \\
\text { - In the last } 6 \text { months }>3 \text { months ( } 8 \text { from } 1 \text { to } 3 \text { times and } 1 \text { for }>3 \text { times) } \\
\text { - In the last } 12 \text { months ( } 12 \text { from } 1 \text { to } 3 \text { times and } 3 \text { for }>3 \text { times) }\end{array}$ & $\begin{array}{c}249 \\
58 \\
34 \\
9 \\
15\end{array}$ & $\begin{array}{l}81.1 \% \\
18.9 \% \\
11 \% \\
2.9 \% \\
4.8 \%\end{array}$ \\
\hline Number of patients accessing ED for pain as main cause & 292 & $95.1 \%$ \\
\hline $\begin{array}{l}\text { Duration of pain determining admission to ED } \\
\text { Less than } 7 \text { days } \\
\text { From } 7 \text { days to } 3 \text { months } \\
\text { More than } 3 \text { months }\end{array}$ & $\begin{array}{c}274 \\
32 \\
1\end{array}$ & $\begin{array}{c}89.2 \% \\
11.7 \% \\
0.3 \%\end{array}$ \\
\hline Number of patients already in home-based analgesic therapy & - & $16.2 \%$ \\
\hline Pain quantification in EAD (NRS scale) & Average & (sd) \\
\hline $\begin{array}{l}\text { Home NRS score pain or NRS declared at Triage } \\
\text { NRS value reported in the visit room }\end{array}$ & $\begin{array}{l}8.2 \\
5.5\end{array}$ & $\begin{array}{l}(\mathrm{sd} 1.5) \\
(\mathrm{sd} 3.3)\end{array}$ \\
\hline Main causes of pain in ED & $\mathrm{N}$ of patients & $\%$ \\
\hline Non-traumatic musculoskeletal & 30 & $9.7 \%$ \\
\hline Traumatic & 88 & $28.6 \%$ \\
\hline Visceral abdominal & 137 & $44.6 \%$ \\
\hline Cancer pain & 3 & $0.9 \%$ \\
\hline Headache & 26 & $8.4 \%$ \\
\hline Post-operative & 1 & $0.3 \%$ \\
\hline Neuropathic pain & 3 & $0.9 \%$ \\
\hline Other causes & 19 & $6.2 \%$ \\
\hline Pain anamnesis & N. of patients & $\%$ \\
\hline
\end{tabular}

Number of acute admissions to ED for analogue pain (number of patients; n, \%)

No admissions to ED in the last 12 months

Admissions in the last 12 months

- In the last 3 months ( 33 from 1 to 3 times and 1 for $>3$ times)

- In the last 6 months $>3$ months ( 8 from 1 to 3 times and 1 for $>3$ times)

- In the last 12 months (12 from 1 to 3 times and 3 for $>3$ times)

Number of patients accessing ED for pain as main cause (number of patients; $n, \%$ )

\begin{tabular}{ccc} 
& 249 & $81.1 \%$ \\
& 58 & $18.9 \%$ \\
34 & $11 \%$ \\
9 & $2.9 \%$ \\
& 15 & $4.8 \%$ \\
& 292 & $95.1 \%$ \\
\hline
\end{tabular}

Duration of pain determining admission to ED (number of patients; $n, \%$ )

Less than 7 days

From 7 days to 3 months

More than 3 months

Number of patients already in home-based analgesic therapy (n, \%)

$89.2 \%$

Pain quantification in EAD (NRS scale) (mean, sd)

Home NRS score pain or NRS declared at Triage

NRS value reported in the visit room

\begin{tabular}{cc}
274 & $89.2 \%$ \\
32 & $11.7 \%$ \\
1 & $0.3 \%$ \\
50 & $16.2 \%$ \\
\hline
\end{tabular}

Main causes of pain in BD

$8.2 \quad 1.5$

5.5

1.5

Non-traumatic musculoskeletal

Traumatic

Visceral abdominal

Cancer pain

Headache

Post-operative

Neuropathic pain

Other causes

$\begin{array}{cc}\text { N. of patients } & \% \\ 30 & 9.7 \% \\ 88 & 28.6 \% \\ 137 & 44.6 \% \\ 3 & 0.9 \% \\ 26 & 8.4 \% \\ 1 & 0.3 \% \\ 3 & 0.9 \% \\ 19 & 6.2 \%\end{array}$


Paracetamol $\square$ NSAIDs $\square$ Minor opioids $\mathbf{a}$ Major opioids $\square$ Lidocaine $\square$ Adjuvants $\square$ No therapy

$100 \%$

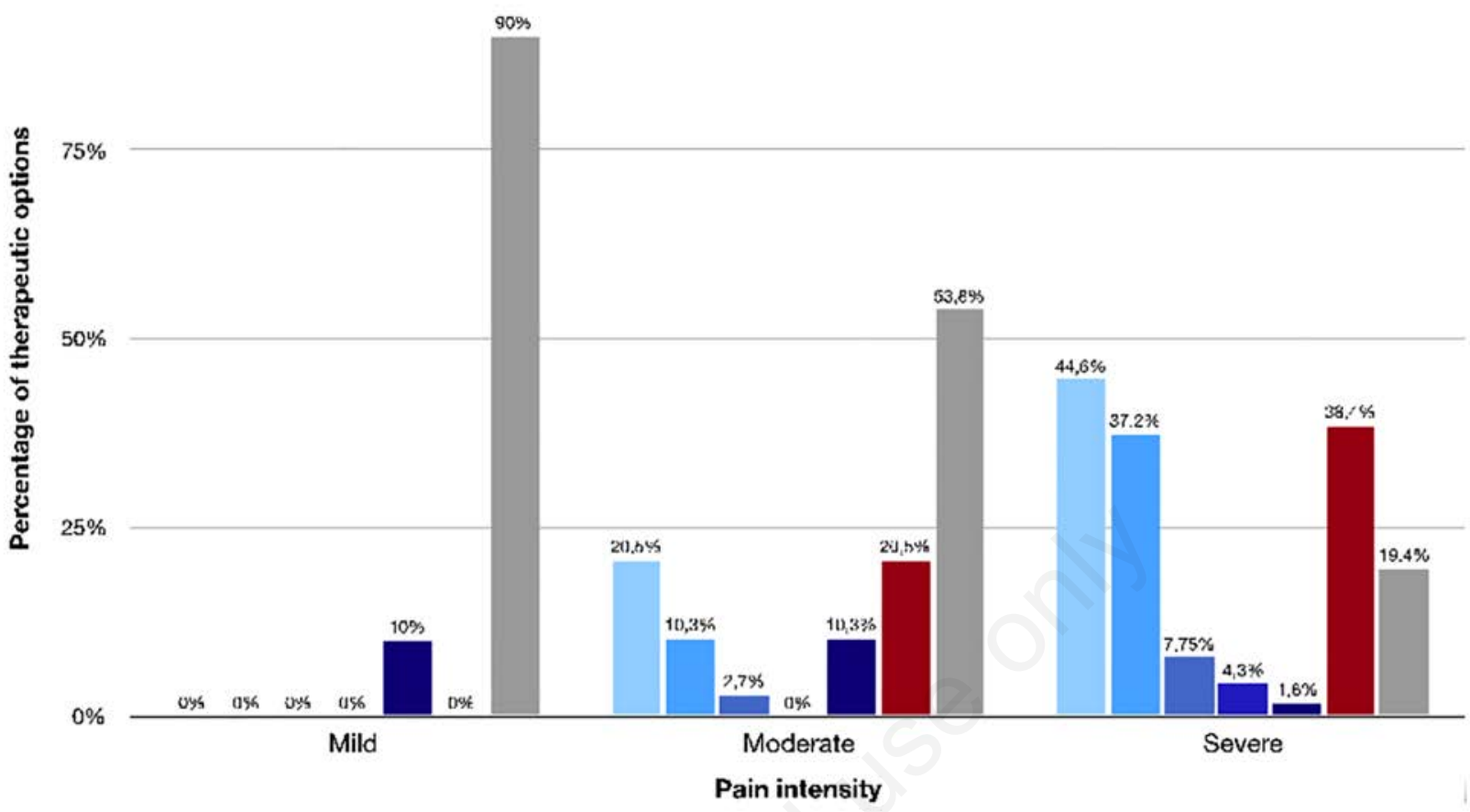

Figure 2. Percentage of therapeutic options for each category of pain intensity. Mild pain intensity means NRS values between 1-3, moderate pain intensity between 4-6, severe pain intensity between 7-10; Minor opioids mainly include tramadol; Major opioids mainly include morphine and sufentanil; Adjuvants include all the drugs administered to give relief to the patient, but without a primarily analgesic action.

Table 3. Pain intensity for the main causes of pain in ED at admission and after visit.

\begin{tabular}{|c|c|c|c|c|c|c|c|c|c|c|c|c|c|}
\hline \multicolumn{14}{|c|}{ Patients complaining of pain at admission (A) and after visit (V) (n 307) } \\
\hline \multicolumn{14}{|c|}{ Pain typology } \\
\hline \multirow[b]{2}{*}{$\begin{array}{l}\text { Time point } \\
\text { NRS score } \\
\text { category }\end{array}$} & \multirow[b]{2}{*}{$\begin{array}{l}\text { NRS } \\
\text { score }\end{array}$} & \multicolumn{2}{|c|}{$\begin{array}{l}\text { Non-traumatic } \\
\text { musculoskeletal } \\
(\mathrm{n}=30 ; 9.7 \%)\end{array}$} & \multicolumn{2}{|c|}{$\begin{array}{l}\text { Traumatic } \\
(\mathrm{n}=88 ; 28.6 \%)\end{array}$} & \multicolumn{2}{|c|}{$\begin{array}{c}\text { Abdominal } \\
\text { (n=137; 44.6\%) }\end{array}$} & \multicolumn{2}{|c|}{$\begin{array}{c}\text { Cancer } \\
\text { (n=3; 0.9\%) }\end{array}$} & \multicolumn{2}{|c|}{$\begin{array}{l}\text { Headache } \\
(\mathrm{n}=26 ; 8.4 \%)\end{array}$} & \multicolumn{2}{|c|}{$\begin{array}{l}\text { Neuropathic } \\
(\mathrm{n}=3 ; 0.9 \%)\end{array}$} \\
\hline & & $\begin{array}{c}\text { A } \\
\text { Count of } \\
\text { pts(n) }\end{array}$ & $\begin{array}{c}\text { T } \\
\text { Count of } \\
\text { pts(n) }\end{array}$ & $\begin{array}{c}\text { A } \\
\text { Count of } \\
\text { pts(n) }\end{array}$ & $\begin{array}{c}\text { T } \\
\text { Count of } \\
\text { pts(n) }\end{array}$ & $\begin{array}{c}\text { A } \\
\text { Count of } \\
\text { pts(n) }\end{array}$ & $\begin{array}{c}\text { T } \\
\text { Count of } \\
\text { pts(n) }\end{array}$ & $\begin{array}{c}\text { A } \\
\text { Count of } \\
\text { pts(n) }\end{array}$ & $\begin{array}{c}\text { T } \\
\text { Count of } \\
\text { pts(n) }\end{array}$ & $\begin{array}{c}\text { A } \\
\text { Count of } \\
\text { pts(n) }\end{array}$ & $\begin{array}{c}\text { T } \\
\text { Count of } \\
\text { pts(n) }\end{array}$ & $\begin{array}{c}\text { A } \\
\text { Count of } \\
\text { pts(n) }\end{array}$ & $\begin{array}{c}\mathrm{T} \\
\text { Count of } \\
\text { pts(n) }\end{array}$ \\
\hline \multirow{4}{*}{ Slight pain } & 0 & 0 & 5 & 0 & 12 & 0 & 29 & 0 & 0 & 0 & 7 & 0 & 1 \\
\hline & 1 & 0 & 0 & 3 & 3 & 0 & 8 & 0 & 1 & 0 & 1 & 0 & 0 \\
\hline & 2 & 1 & 1 & 1 & 3 & 0 & 14 & 0 & 0 & 0 & 3 & 0 & 0 \\
\hline & 3 & 1 & 3 & 4 & 8 & 1 & 16 & 0 & 0 & 0 & 1 & 0 & 0 \\
\hline \multirow{3}{*}{ Moderate pain } & 4 & 1 & 5 & 1 & 9 & 4 & 10 & 0 & 0 & 0 & 4 & 4 & 1 \\
\hline & 5 & 3 & 6 & 10 & 13 & 2 & 23 & 0 & 0 & 3 & 4 & 0 & 0 \\
\hline & 6 & 1 & 4 & 9 & 15 & 4 & 9 & 0 & 0 & 0 & 1 & 0 & 0 \\
\hline \multirow[t]{4}{*}{ Severe pain } & 7 & 4 & 2 & 13 & 8 & 24 & 17 & 1 & 1 & 3 & 1 & 0 & 1 \\
\hline & 8 & 5 & 3 & 27 & 11 & 38 & 6 & 0 & 0 & 6 & 2 & 2 & 0 \\
\hline & 9 & 6 & 1 & 11 & 2 & 18 & 4 & 0 & 1 & 6 & 1 & 1 & 0 \\
\hline & 10 & 5 & 0 & 10 & 5 & 46 & 1 & 2 & 0 & 8 & 1 & 0 & 0 \\
\hline \multirow[t]{2}{*}{ Time point } & & $\begin{array}{c}\text { A } \\
\text { NRS }\end{array}$ & $\begin{array}{c}\mathrm{T} \\
\text { NRS }\end{array}$ & $\begin{array}{c}\text { A } \\
\text { NRS }\end{array}$ & $\begin{array}{c}\mathrm{T} \\
\text { NRS }\end{array}$ & $\begin{array}{c}\text { A } \\
\text { NRS }\end{array}$ & $\begin{array}{c}\text { T } \\
\text { NRS }\end{array}$ & $\begin{array}{c}\text { A } \\
\text { NRS }\end{array}$ & $\begin{array}{c}\mathrm{T} \\
\text { NRS }\end{array}$ & $\begin{array}{c}\text { A } \\
\text { NRS }\end{array}$ & $\begin{array}{c}\mathrm{T} \\
\text { NRS }\end{array}$ & $\begin{array}{c}\text { A } \\
\text { NRS }\end{array}$ & $\begin{array}{c}\mathrm{T} \\
\text { NRS }\end{array}$ \\
\hline & & $\begin{array}{l}\text { mean } \\
(\text { sd) }\end{array}$ & $\begin{array}{l}\text { mean } \\
(\text { sd) }\end{array}$ & $\begin{array}{l}\text { mean } \\
\text { (sd) }\end{array}$ & $\begin{array}{l}\text { mean } \\
\text { (sd) }\end{array}$ & $\begin{array}{l}\text { mean } \\
(\text { sd) }\end{array}$ & $\begin{array}{l}\text { mean } \\
\text { (sd) }\end{array}$ & $\begin{array}{l}\text { mean } \\
\text { (sd) }\end{array}$ & $\begin{array}{l}\text { mean } \\
\text { (sd) }\end{array}$ & $\begin{array}{l}\text { mean } \\
\text { (sd) }\end{array}$ & $\begin{array}{l}\text { mean } \\
(\text { sd) }\end{array}$ & $\begin{array}{l}\text { mean } \\
\text { (sd) }\end{array}$ & $\begin{array}{l}\text { mean } \\
(\mathrm{sd})\end{array}$ \\
\hline \multicolumn{2}{|l|}{$\begin{array}{l}\text { NRS mean } \\
\text { (sd) }\end{array}$} & $\begin{array}{c}7.4 \\
(\operatorname{sd~2.1)}\end{array}$ & $\begin{array}{c}4.4 \\
(\operatorname{sd} 2.6)\end{array}$ & $\begin{array}{c}7.1 \\
(\operatorname{sd} 2.2)\end{array}$ & $\begin{array}{c}4.9 \\
(\operatorname{sd} 2.9)\end{array}$ & $\begin{array}{c}8.3 \\
\text { (sd 1.6) }\end{array}$ & $\begin{array}{c}3.7 \\
(s d 2.7)\end{array}$ & $\begin{array}{c}9 \\
(\operatorname{sd~1.7)}\end{array}$ & $\begin{array}{c}6 \\
(\operatorname{sd} 3.6)\end{array}$ & $\begin{array}{c}8.4 \\
(s d 1.6)\end{array}$ & $\begin{array}{c}3.6 \\
(\operatorname{sd} 3.1)\end{array}$ & $\begin{array}{c}8.3 \\
\operatorname{sd} 0.5)\end{array}$ & $\begin{array}{c}3.7 \\
(\operatorname{sd} 3.5)\end{array}$ \\
\hline \multicolumn{2}{|l|}{$\mathrm{p}$ value } & \multicolumn{2}{|c|}{$p<0.0001$} & \multicolumn{2}{|c|}{$p<0.0001$} & \multicolumn{2}{|c|}{$p<0.0001$} & \multicolumn{2}{|c|}{$p>0.05$} & \multicolumn{2}{|c|}{$\mathrm{p}<0.0001$} & \multicolumn{2}{|c|}{$p>0.05$} \\
\hline
\end{tabular}

Counts of patients distinctly by pain typology, by time point, by pain intensity are reported in the first part of the table. Descriptive statistics (mean and sd) of the NRS score, reported distinctly by pain typology and by time point, are shown at the bottom of the table. Post-operative pain was excluded because regarded only one patient. A: Admission; T: After Treatment; NRS: Numerical Rating Scale. 
given lidocaine. Among those with moderate pain severity, percentage of patients not receiving any treatment decreases $(53.8 \%)$, while the usage of Paracetamol and NSAIDs increases; the use of Lidocaine is almost the same. In the last and most consistent group of people complaining of severe pain, the number of untreated patients decreases further (19.4\%) together with the use of Lidocaine, while Paracetamol and NSAIDs show a growing trend. Opioids administration, both minor and major opioids, also increases in this group ( $7.75 \%$ and $4.3 \%$ respectively); however, the rate of increase turns out to be very low compared to the standards of medical community. Finally, use of adjuvant therapy of any type shows an increasing trend from the first to the third group.

\section{Patient's satisfaction}

The evaluation of patient's satisfaction with respect to treatment administered by doctors and nurses was investigated by a customer satisfaction analysis administered once the treatment was completed, i.e. before discharge. The patient is requested to report a value between 1 and 10 to evaluate respectively nurse management, medical treatment, general treatment and adequacy of information. In case of dissatisfaction, we enquired the reason. We considered unsatisfied those patients who reported a score below 6 . Only 6 patients $(1.9 \%$ of the total) indicated they were not satisfied of nurse treatment, and the mean reported score is 8.9 (sd 1.7). Concerning medical treatment, results are quite comparable: only 7 patients $(2.2 \%)$ said to be not satisfied, and the total average score is 8.9 (sd 1.4). Finally, patients have been asked about level of satisfaction about general treatment: in this case, 35 patients reported not to be satisfied, equivalent to $11.4 \%$ of the total. It is quite evident that many factors other than merely medical treatment have been influencing this parameter, such as the long waiting times, organization and logistics.

We then investigated whether patients received adequate information about analgesic treatment. In this category, results appear to be worse: indeed, 141 patients $(45.9 \%)$ believe they did not receive appropriate information. Therefore, it is apparent that, since nearly half of the patients conveyed this critical issue, this is certainly an aspect that needs to be improved, for instance by informative papers or by education of ED personnel to improve their communicative skills.

Causes of dissatisfaction can be basically classified into four categories: i) I did not receive any drug; ii) Lack of care/attention toward the symptoms by medical personnel; iii) Inadequate information and explanations; iv) Prolonged waiting times.

Conclusively, we analysed the association between level of satisfaction and administration of analgesic therapy. Almost all patients who did not receive any therapy were satisfied with medical, nurse and general treatment. All the patients who reported to be not satisfied actually received analgesic therapy, that eventually turned out to be inadequate. Therefore, no association was observed between the actual administration of a therapy and patient's satisfaction (as already described in literature). ${ }^{13}$

\section{Conclusions}

From our data, we can infer that the dispensed pharmacological treatments are quite effective in reducing pain intensity, with statistically significant results. However, improvement in the choice of pharmacological options is still required since a tendency toward insufficient use of opioids has emerged. As to treatment, data about specific drugs used for analgesia have been analysed. A correlation between prevalence of analgesia and potency of anal- gesic drugs used with respect to pain intensity was highlighted. However, the percentage of patients not receiving treatment was still high (nearly 20\%) among those reporting NRS values higher than 7 , and prevalence of opioids administration is generally low even in this group: $7.75 \%$ for minor opioids, $4.3 \%$ for major opioids. Therefore, although a correlation between analgesic potency and pain severity is present, oligoanalgesia is still a consistent problem in our ED, especially for what concerns opioids. Our data are comparable to the overall Italian situation. It is widely known that Italy has always been one of the countries with the lowest use of opioids: for instance, in 2005 the percentage of Italian pharmaceutical expenditure for opioids was $0.6 \%$ of the total expenditure for drugs and was superior to Greece and Portugal ones but lower than that those of other European countries, such as Germany $(3.8 \%)$ and UK (3.9\%), ${ }^{14}$ so much that some epidemiologists have created a neologism: morphine-phobia. This situation was almost constant also in the following years until 2010, and placed Italy among the countries of the world with a low (inadequate) consumption of opioid analgesics, at least 5 times lower than the consumption needed.

In 2010, a law on palliative care and pain therapy was approved, which simplified the use of opioids and the use of opioid analgesic drugs in Italy has increased by 26\% from 2012 and 2014. However, Italy remains in the list of countries with the lowest consumption of opioid analgesics in Europe, around $2 \mathrm{mg}$ per capita per year. ${ }^{15}$ This is again below the European average $(12.6 \mathrm{mg})$ and the world mean $(6.0 \mathrm{mg})$. Furthermore, WHO has chosen, through the International Narcotic Control Band, the use of morphine as a quality parameter for National Health Systems, for which our performance is quite modest. On the contrary, Italy is the European country with the greatest use of NSAIDs, as a percentage of the total number of analgesics used.

The second parameter to be improved is time-to-analgesia, since the target recommended by guidelines is 30 minutes from access to ED, while our results show that almost $1 / 4$ of patients reported a larger waiting time and another group of patients never received treatment even after asking for it. A peculiar problem in ED is being able to guarantee promptness of analgesic treatment which is often hindered by waiting times, usually quite long especially for low priority code patients. Time-to-analgesia is indeed a quality marker for emergency units. ${ }^{16}$ Recommendations would be to reduce this value as much as possible until the threshold of 30 minutes within the arrival to ED. However, in the literature, we still find many variable data, with some studies stating an average time-to-analgesia of more than 70 minutes for traumas. ${ }^{17}$

Results concerning level of satisfaction on medical and nursing care are quite excellent; however, almost half of enrolled patients have reported lack of information about pain management. This aspect leaves large space for progress, either by offering the patients specific folders on the matter, or urging, through explicit training, health care personnel to improve their communication skills the use of informative material or by education of the health care personnel to improve their communicative skills. In order to properly take care of pain, it is first needed to establish an effective communication and empathic relationship with the patient, taking into account all the components that play a role in the experience of pain. The outcomes of the survey are only partially reported in this article, because some of them gave rise to a different approach and significant practical hints in the management of pain in Emergency. In particular, we started a protocol for early pain management in triage, carried out by nurses through the administration of paracetamol to all the patients presenting with pain within specific criteria. Moreover, we organized training courses for doctors 
and nurses focused on improving their compliance to a correct approach in recording and treating pain, with respect to any specific disease. Pain management is not only an ethical duty, but also an indicator of the good clinical practice and a right for the ill person.

*On behalf of OSM acute pain assessment lab: William Brambilla, Lorenzo Demitry, Gianmarco Secco, Alice Bruno, Maria Mascolo, Ilaria Melara, Maria Serena Pioli Di Marco (Residents in Emergency Medicine, University of Pavia, Pavia, Italy) and Alexandra Asrow (NorthShore University Healthsystem, Chicago, IL, USA).

\section{References}

1. Savoia G, Coluzzi F, Di Maria C, Ambrosio F, Della Corte F, Oggioni $\mathrm{R}$, et al. Italian intersociety recommendations on pain management in the emergency setting (SIAARTI, SIMEU, SIS 118, AISD, SIARED, SICUT, IRC). Minerva Anestesiol 2015;81:205-25.

2. Wilson JE, Pendleton JM. Oligoanalgesia in the emergency department. Am J Emerg Med 1989;7:620-3.

3. Tanabe P, Buschmann M. A prospective study of ED pain management practices and the patient's perspective. J Emerg Nurs 1999;25:171-7.

4. Grant PS. Analgesia delivery in the ED. Am J Emerg Med 2006;24:806-9.

5. Todd KH, Ducharme J, Choiniere M, Crandall CS, Fosnocht DE, Homel P, et al. pain in the emergency department: results of the pain and emergency medicine initiative (PEMI) Multicenter Study. J Pain 2007;8:460-6.

6. Stang AS, Hartling L, Fera C, Johnson D, Ali S. Quality indicators for the assessment and management of pain in the emergency department: a systematic review. Pain Res Manag 2014;19:e179-90.

7. Ritsema TS, Kelen GD, Pronovost PJ, Pham JC. The national trend in quality of emergency department pain management for long bone fractures. Academic Emerg Med 2007;14:163-9.

8. Vazirani J, Knott JC. Mandatory pain scoring at triage reduces time to analgesia. Ann Emerg Med 2012;59:134-138.e2.

9. Lynch ME. The need for a canadian pain strategy. Pain Res Manag 2011;16:77-80.

10. Breivik EK, Björnsson GA, Skovlund E. A comparison of pain rating scales by sampling from clinical trial data. Clin J Pain $2000 ; 16: 22-8$.

11. World Medical Association Declaration of Helsinki. Ethical principles for medical research involving human subjects. JAMA 2013;310:2191.

12. Von Elm E, Altman DG, Egger M, Pocock SJ, Gøtzsche PC, Vandenbroucke JP. The strengthening the reporting of observational studies in epidemiology (STROBE) statement: guidelines for reporting observational studies. Lancet 2007;370:1453-7.

13. Shirley ED, Sanders JO. Measuring quality of care with patient satisfaction scores. J Bone Joint Surg 2016;98:e83.

14. International Narcotics Control Board. Estimated world requirements for 2005, statistics for 2003. New York: INCB; 2005.

15. The Medicines Utilisation Monitoring Centre. National Report on Medicines use in Italy. Year 2018. Rome: Italian Medicines Agency; 2019.

16. Hatherley C, Jennings N, Cross R. Time to analgesia and pain score documentation best practice standards for the Emergency Department - A literature review. Australasian Emerg Nurs J 2016;19:26-36.

17. Heilman JA, Tanski M, Burns B, Lin A, Ma J. Decreasing time to pain relief for emergency department patients with extremity fractures. BMJ Qual Improv Report 2016;5:u2095 22.w7251. 